\title{
TERAMPIL
} Jurnal Pendidikan dan Pembelajaran Dasar

\section{PENGEMBANGAN MODEL PEMBELAJARAN LARI CEPAT MELALUI PERMAINAN UNTUK MENINGKATKAN HASIL BELAJAR LARI CEPAT PADA SISWA SD KELAS V} RACHMAT DODY ARIESNA

Email: dodiariesna@gmail.com STKIP Al Islam Tunas Bangsa RELLYA RUNASARI

Email: rere.rellya@yahoo.com STKIP Al Islam Tunas Bangsa Volume 6 Nomor 1, Juni 2019

\begin{abstract}
Abstrak
This study aims to improve the results of sprint learning by developing a sprint learning model through games in elementary school class $V$ students. Research \& development in this study uses a Research \& Development $(R \& D)$ development model from Borg and Gall. This research was conducted at SDN 8 Gedung Air Kota Bandar Lampung, with the target of the client (Target Clientele) is a class $V$ student numbering 30 students and elementary school teachers as a reference in teaching. The results of the study are a form of sprint learning model, among others (1) M-form play, (2) down game, (3) squat game, (4) applause game, (5) tap ladder game. Analysis of the results of psychomotor scores found that students who obtained a score of $\geq 80 \%$ (very good) were 18 students and grades 60-79 (good) were 12 students and all were declared graduated. With this it can be concluded that the sprint learning model through the game has been successfully mastered and can improve the results of sprint learning in elementary school class $V$ students.
\end{abstract}

Keywords: The Results of Learning, Run Fast, The Development of Learning Model

Abstrak

Penelitian ini bertujuan untuk meningkatkan hasil belajar lari cepat dengan mengembangkan model pembelajaran lari cepat melalui permainan pada siswa SD kelas V. Penelitian \& pengembangan dalam pembelajaran ini menggunakan model pengembangan Research \& Development $(R \& D)$ dari Borg dan Gall. Penelitian ini dilaksanakan di SDN 8 Gedung Air Kota Bandar Lampung, dengan sasaran klien (Target Clientele) adalah siswa kelas V berjumlah 30 siswa dan guru sekolah dasar sebagai acuan dalam mengajar. Hasil penelitian merupakan bentuk model pembelajaran lari cepat antara lain (1) permainan bentuk M, (2) permainan tiarap, (3) permainan jongkok, (4) permainan tepuk tangan, (5) permainan tangga tepuk. Analisis hasil nilai psikomotorik didapatkan siswa yang memperoleh nilai $\geq 80 \%$ (sangat baik) adalah 18 siswa dan nilai 60-79 (baik) adalah 12 siswa dan semua dinyatakan lulus. Dengan ini dapat disimpulkan model pembelajaran lari cepat melalui permainan telah berhasil dikuasai dan dapat meningkatkan hasil belajar lari cepat pada siswa sekolah dasar kelas V.

Kata Kunci: Hasil Belajar, Lari Cepat, Pengembangan Model Pembelajaran 


\section{A. PENDAHULUAN}

Aip Syaifudin dan Muhadi, (1992:20) dalam (Asih, 2015), program pembelajaran pendidikan jasmani yang diselenggarakan di sekolah hendaknya mampu menciptakan berbagai bentuk ketrampilan dasar bagi gerak anak kelas pemula sekolah dasar, maka akan meningkatkan aktivitas pengembangan kemampuan jasmani. Faktor keberhasilan dalam proses pembelajaran diantaranya bagaimana guru dalam memberikan materi pembelajaran pada siswanya, sehingga siswa dapat menyenangi dan memahami apa yang telah disampaikan oleh guru.

Berdasarkan kenyataan yang terjadi saat ini, pembelajaran yang disampaikan guru pendidikan jasmani pada Sekolah Dasar saat ini sebagian besar kurang memperhatikan gerak dasar yang dibutuhkan siswanya, pemberian tugas tertulis lari cepat, tanpa mengenalkan gerak dasar yang diperlukan anak tersebut atau yang sesuai dengan karakter fisik dan emosi anak.

Menurut (Jerry R \& T.Thomas, 2008), seorang anak dapat melakukan aktivitas fisik dengan bertenaga namun secara alami dan dapat menikmati permainan dengan senang. Gerak dalam bermain merupakan wahana untuk memacu dan memotivasi untuk mendorong dan merangsang masalah belajar, melalui belajar gerak memacu anak untuk berfikir dan mengetahui terhadap mengapa dan bagaimana, sehingga bermain merupakan peranan penting dalam perkembangan dan pengetahuan serta perkembangan pengamatan anak. Menurut Djumidar, Lari adalah frekuensi langkah yang dipercepat sehingga pada waktu berlari ada kecenderungan badan melayang, yang dimana pada waktu lari kedua kaki tidak menyentuh tanah sekurang-kurangnya satu kaki tetap menyentuh tanah (Widy, 2004).

Guru pendidikan jasmani haruslah lebih kreatif dalam memberikan pembelajaran pendidikan jasmani, khususnya dalam pembelajaran lari cepat, agar setiap materi yang diberikan membuat anak didiknya bersemangat dan senang dalam pembelajaran lari cepat tersebut. Salah satu kompetensi dasar kelas V adalah mempraktikkan gerak dasar kedalam modifikasi atletik, serta nilai kerjasama, sportivitas dan kejujuran.

Menurut Gilang dalam (Ramadhan, 2017), dalam pendidikan jasmani, atletik merupakan salah satu cabang olahraga yang sudah lama dikenalkan, dan sudah dikenal oleh banyak orang didunia. Gerakangerakan yang terdapat didalam cabang atletik merupak gerakan yang memang sering dilakuakn manusia dalam kehidupan sehari - hari. Selain itu, gerak-gerakannya juga merupakan dasar gerakan dari olahraga lain. Di samping itu, guru Sekolah Dasar diharapkan dapat memodifikasi peralatan dan tempat sedemikian rupa dalam pembelajaran, yang dapat digunakan dalam ruang sekolah yang luas bahkan ruang sekolah yang kurang luas sekalipun untuk keberhasilan pembelajaran. Karena setiap tempat dan peralatan tiap-tiap sekolah tidak sama, ada yang mempunyai tempat yang luas bahkan ada yang tidak mempunyai tempat dalam pembelajaran pendidikan jasmani.

Modifikasi pembelajaran penididikan jasmani yang diberikan guru Sekolah 
Dasar dan juga memodifikasi tempat serta peralatannya, diharapkan juga dapat tumbuh atlet-atlet muda khususnya atlet lari cepat yang bermunculan dari sekolah-sekolah, sehingga atlet muda lari cepat tidak hanya berasal dari klub-klub atletik seperti yang selama ini terjadi.

Berdasarkan penelitian terdahulu, penelitian tentang pengembangan model pembelajaran melalui permainan sudah banyak diteliti, seperti penelitian yang dilakukan oleh (Badu, 2011; Febrianti, 2013; HAPIDIN \& YENINA, 2016; Munawaroh, 2017; Munendra \& Lumintuarso, 2015; Novitasari, Supurwoko, \& Surantoro, 2013; Yumarlin, 2013) serta ada penelitian dari Akhmad tentang model pembelajaran melalui permainan yang berpengaruh terhadap hasil belajar (Afandi, 2015; Sukri \& Purwanti, 2009). Namun, belum ada penelitian yang mengembangkan model pembelajaran lari cepat untuk meningkatkan hasil belajar lari cepat. Maka, penulis mengambil kesimpulan diperlukan pengembangan pembelajaran yang dapat memberikan motivasi belajar serta bermanfaat, menarik dan efektif pada pembelajaran lari cepat, serta memberikan kemudahan kepada guru pendidikan jasmani dalam menyampaikan materi. Untuk mengatasi permasalahan diatas perlu dikembangkan model pembelajaran lari cepat melalui permainan pada anak Sekolah Dasar kelas V.

\section{B. METODE PENELITIAN}

Tujuan akhir dari penelitian pengembangan ini adalah menghasilkan model pembelajaran lari cepat melalui permainan untuk meningkatkan hasil belajar lari cepat pada siswa Sekolah Dasar kelas V, sehingga dapat melengkapi pembelajaran yang ada pada saat ini yakni, agar dalam belajar siswa dapat lebih: efektif, efisiensi dan menarik. Penelitian ini dilaksanakan di SDN 8 Gedung Air Kota Bandar Lampung tahun 2018, dengan sasaran klien (Target Clientele) adalah siswa kelas $\mathrm{V}$ berjumlah 30 orang dan guru sekolah dasar sebagai acuan dalam mengajar.

Penelitian dan pengembangan dalam pembelajaran ini menggunakan model pengembangan Research \& Development $(R \& D)$ dari Borg dan Gall yang terdiri dari sepuluh langkah.

Instrumen yang digunakan dalam penelitian ini adalah dengan menggunakan angket untuk analisis kebutuhan, kuesioner evaluasi ahli/pelatih atletik, kuesioner evaluasi ahli pembelajaran pendidikan jasmani dan hasil penilaian siswa (dalam uji coba tahap I dan uji coba tahap II) dan tes psikomotorik lari cepat. Teknik analisis data menggunakan teknik analisis deskriptif kuantitatif dengan persentase. Teknik ini digunakan untuk menganalisa data kuantitatif yang diperoleh dari hasil penyebaran angket evaluasi dari ahli/pelatih atletik dan ahli pembelajaran pendidikan jasmani mengenai hasil produk yang dikembangkan.

\section{HASIL PENELITIAN DAN PEMBAHASAN \\ 1. Analisis Data dari Ahli/Pelatih Atletik}

Berdasarkan hasil analisis evaluasi ahli/pelatih atletik bahwa: diketahui jumlah total skor responden $\left(\sum \mathrm{X}\right)$ adalah 125 dan jumlah total keseluruhan skor responden $\left(\sum \mathrm{X} 1\right)$ 


\section{RACHMAT DODY ARIESNA \& RELLYA RUNASARI}

adalah 144. Sehingga, persentasenya adalah $86,11 \%$.

Berdasarkan hasil analisis yang telah dilakukan terhadap tanggapan/penilaian dari ahli/pelatih atletik, hasilnya adalah $86,11 \%$, dari kriteria yang ditentukan dan dapat dikatakan bahwa Model Pembelajaran Lari Cepat melalui Permainan ini memenuhi kriteria VALID (80\% - 100\%) sehingga dapat digunakan dan dipraktekkan dalam proses pembelajaran di sekolah dasar.

2. Analisis Data dari Ahli Pembelajaran Pendidikan Jasmani

Berdasarkan hasil analisis evaluasi ahli pembelajaran penjas bahwa: diketahui jumlah total skor responden $\left(\sum X\right)$ adalah 62 dan jumlah total keseluruhan skor responden $\left(\sum \mathrm{X} 1\right)$ adalah 72 . Sehingga, persentasenya adalah $86,11 \%$.

Berdasarkan hasil analisis yang dilakukan terhadap tanggapan/penilaian dari ahli pembelajaran penjas, hasilnya adalah $86,11 \%$, dari kriteria yang ditentukan dan dapat dikatakan bahwa Model Pembelajaran Lari
Cepat melalui Permainan ini memenuhi kriteria VALID $(80 \%$ $100 \%$ ) sehingga dapat digunakan dan dipraktekkan dalam proses pembelajaran di sekolah dasar.

\section{Data Kelulusan dan Keberhasilan Pembelajaran Siswa kelas V}

Untuk mengetahui hasil produk berupa pembelajaran lari cepat melalui permainan yang di uji cobakan ke para siswa Sekolah Dasar kelas $\mathrm{V}$ apakah sudah berhasil atau belum, maka harus diperoleh data tentang kemampuan psikomotorik siswa dalam menguasai pembelajaran lari cepat melalui permainan ini . Pengumpulan data ini dilakukan pada saat uji kelompok kecil dan uji coba lapangan utama. Berikut akan di sajikan data-data tersebut secara ringkas:

\section{a. Data Nilai Uji Coba Kelompok Kecil}

\section{Data Nilai Psikomotorik}

Data nilai psikomotorik dari siswa Sekolah Dasar kelas V pada uji coba kelompok kecil dapat dilihat pada Tabel 1.

Tabel 1

Tingkat Kelulusan Siswa dalam Menguasai Materi Psikomotorik

\begin{tabular}{cccc}
\hline Nilai & Kategori & Makna & Jumlah \\
$\geq 80 \%$ & Sangat baik & Lulus & 1 orang \\
$60-79 \%$ & Baik & Lulus & 9 orang \\
$40-59 \%$ & Cukup & Tidak Lulus & 0 \\
$30-39 \%$ & Kurang & Tidak Lulus & 0 \\
$<29 \%$ & Sangat kurang & Tidak Lulus & 0 \\
& Jumlah siswa & 10 orang \\
& Jumlah Siswa yang Lulus & 10 orang \\
\hline
\end{tabular}

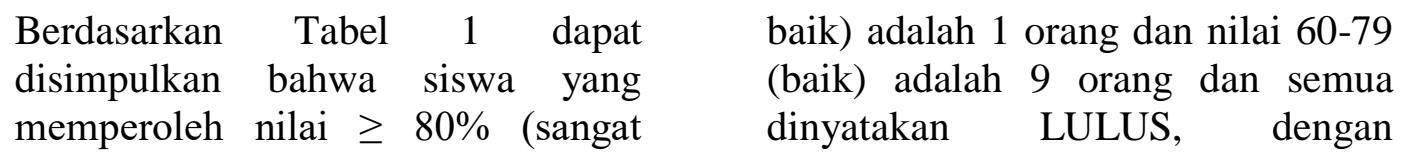




\section{RACHMAT DODY ARIESNA \& RELLYA RUNASARI}

demikian disimpulkan bahwa Data Nilai Psikomotorik

instrumen psikomotorik dalam Data nilai psikomotorik dari siswa pembelajaran lari cepat melalui permainan dapat digunakan dalam uji coba lapangan (kelompok besar). b. Data Nilai Uji Coba Kelompok Besar (Lapangan)

Sekolah Dasar kelas V pada uji coba kelompok besar dapat dilihat pada tabel dibawah ini:

Tabel 2

Tingkat Kelulusan Siswa Menguasai Materi Psikomotorik

\begin{tabular}{cccc}
\hline Nilai & Kategori & Makna & Jumlah \\
$\geq 80 \%$ & Sangat baik & Lulus & 18 orang \\
$60-79 \%$ & Baik & Lulus & 12 orang \\
$40-59 \%$ & Cukup & Tidak Lulus & 0 \\
$30-39 \%$ & Kurang & Tidak Lulus & 0 \\
$<29 \%$ & Sangat kurang & Tidak Lulus & 0 \\
& Jumlah Siswa & 30 orang \\
& Jumlah Siswa yang Lulus & 30 orang \\
& Jumlah Siwa yang Tidak Lulus & 0 \\
\hline
\end{tabular}

$\begin{array}{lccccr}\text { Berdasarkan } & \text { Tabel } 2 & \text { dapat } & \text { demikian dapat disimpulkan bahwa } \\ \text { disimpulkan bahwa, siswa yang } & \text { materi psikomotorik } & \text { dalam } \\ \text { memperoleh nilai } \geq 80 \% \text { (sangat } & \text { pembelajaran lari cepat melalui } \\ \text { baik) adalah } 18 \text { orang dan nilai } 60-79 & \text { permainan telah berhasil dikuasai } \\ \text { (baik) adalah } 12 \text { orang dan semua } & \text { siswa }\end{array}$
dinyatakan LULUS, dengan

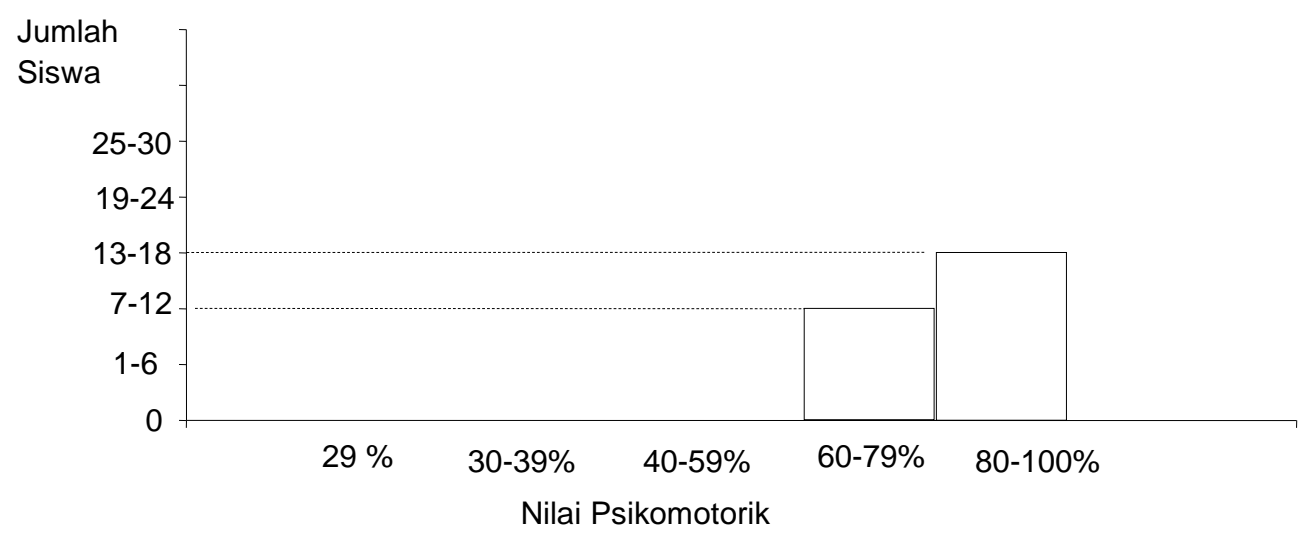

Gambar 1. Histogram Nilai Psikomotor (Uji Coba Lapangan)

\section{SIMPULAN DAN SARAN}

Berdasarkan data yang didapat, dari hasil uji coba lapangan dan pembahasan hasil penelitian dapat disimpulkan sebagai berikut: (1) Dengan model pembelajaran lari cepat melalui permainan siswa dapat belajar secara efektif dan efisien, (2) Dengan materi pembelajaran yang telah peneliti kembangkan, siswa dapat menyenangi pembelajaran lari cepat, (3) Dengan adanya pembelajaran lari cepat melalui permaianan yang telah peneliti kembangkan dapat sebagai acuan 
bahan ajar bagi guru Sekolah Dasar khususnya kelas V.

Berdasarkan kesimpulan diatas, penelitian pengembangan model pembelajaran lari cepat melalui permainan untuk meningkatkan hasil belajar lari cepat ini menyarankan untuk pengembangan penelitian selanjutnya sebagai berikut: (1) lebih dikembangkan lagi materi pembelajaran yang telah peneliti kembangkan agar lebih optimal lagi dalam menarik siswa di pembelajaran lari cepat, (2) produk model pembelajaran lari cepat berupa bahan ajar permainan lari cepat agar dimodifikasi kembali sesuai identifikasi kebutuhan siswa dan standar kompetensi /kompetensi dasar.

\section{E. DAFTAR PUSTAKA}

Afandi, R. (2015). Pengembangan Media Pembelajaran Permainan Ular Tangga untuk Meningkatkan Motivasi Belajar Siswa dan Hasil Belajar IPS di Sekolah Dasar. Jinop (Jurnal Inovasi Pembelajaran), 1(1), 77.

Asih, K. P. (2015). Pembelajaran Lari Cepat melalui Permainan Bentengan untuk Meningkatkan Partisipasi dalam Pembelajaran Penjasorkes Pada Siswa Kelas Iii SD Negeri 2 Randublatung Kabupaten Blora 2013/2014. Active - Journal of Physical Education, Sport, Health And Recreation, 4(1), 1554-1559.

Badu, R. (2011). Pengembangan Model Pelatihan Permainan Tradisional Edukatif Berbasis Potensi Lokal dalam Meningkatkan Kemampuan dan Keterampilan Orang Tua Anak Usia Dini di PAUD Kota
Gorontalo. Jurnal Penelitian dan Pendidikan, 8(1), 70-77.

Febrianti, R. (2013). Pengembangan Materi Atletik melalui Permainan Atletik Three In One Untuk Siswa SD Kelas V. Journal of Physical Education And Sports, 2(1), 193-199.

Hapidin, \& Yenina. (2016). Pengembangan Model Permainan Tradisional dalam Membangun Karakter Anak Usia Dini. Jurnal Pendidikan Usia Dini, 10(2), 201-212.

Jerry R, T., \& T.Thomas, K. (2008). Psysical Education Methods For Elementary Teachers. United States of America: Human Kinetics.

$\begin{array}{cr}\text { Munawaroh, } & \text { H. } \\ \begin{array}{c}\text { Pengembangan } \\ \text { Pembelajaran }\end{array} & \text { Model } \\ \text { Pengan }\end{array}$

Permainan Tradisional Engklek sebagai Sarana Stimulasi Perkembangan Anak Usia Dini. Jurnal Obsesi : Journal of Early Childhood Education, 1(2), 6.

Munendra, A. W., \& Lumintuarso, R. (2015). Pengembangan Model Pembelajaran Lempar Lembing untuk Siswa Sekolah Menengah Pertama (SMP). Jurnal Keolahragaan, 3(2), 127-138.

Novitasari, E., Supurwoko, \& Surantoro. (2013). Pengembangan Media Pembelajaran Berbasis IT Berbentuk Permainan Ular Tangga Materi Alat Optik untuk Kelas VIII SMP. Jurnal Pendidikan Fisika, 1(1), 37-45. Ramadhan, G. (2017). Meningkatkan Rangkaian Gerak Lompat Tinggi Melalui Metode Jigsaw dan Pembelajaran yang Dikemas dalam Bentuk Permainan. SP ORTIVE, 
RACHMAT DODY ARIESNA \&

RELLYA RUNASARI

2(1), 61-70.

Sukri, A., \& Purwanti, E. (2009).

Meningkatkan Hasil Belajar Siswa melalui Brain Gym. Jurnal Edukasi Matematika dan Sains, 1(1), 50-57.

Widy, M. D. A. (2004). Belajar Berlatih Gerak-Gerak Dasar Atletik dalam Bermain. Jakarta: PT. Raja Grafinda Persada.

Yumarlin, M. (2013). Pengembangan Permainan Ular Tangga. Jurnal Teknik, 3(1), 75-84. 